\title{
Managing irrigation of fruit trees using plant water status
}

\author{
Rashid Al-Yahyai \\ Department of Crop Sciences, College of Agricultural and Marine Sciences, Sultan Qaboos University, Muscat, Sultanate of Oman; \\ alyahyai@squ.edu.om
}

Received 24 September 2011; revised 29 November 2011; accepted 12 December 2011

\begin{abstract}
Optimum growth and production of fruit crops is strongly linked to managing irrigation water. Various method of estimating tree water requirements have been utilized such as direct and indirect soil, water, and climatic measurements. Due to differences in fruit tree anatomical and morphological structures and their adaptation to excess and deficit soil water content, such estimates of irrigation water requirements may be more suitable for herbaceous plants but not as accurate for trees. Studies on temperate and tropical fruit trees, using apple (Malus domestica) and star-fruit (Averrhoa carambola), respectively, showed that tree water potential is highly correlated to soil water status. Irrigation based on climate data (ET) and monitoring of soil water resulted in no significant differences in soil or tree water status of orchard-grown fruit trees under temperate and subtropical climatic conditions. The results indicated the need for better understanding and utilization of tree physiological parameters for management of irrigation water of fruit crops. This will ultimately lead to achieving optimum yield and fruit quality while conserving water resources.
\end{abstract}

Keywords: Apple; Star-Fruit; Water Potential; Water Content; Tree Physiology; Temperate; Tropics; Irrigation Scheduling; Tree Water Status

\section{INTRODUCTION}

Irrigation is a vital management practice in fruit production regions of the world, particularly in arid and semi-arid climates. Despite the variations in the available water resources among fruit producing countries, the question of frequency of irrigation and amount of water applied to fruit crops is a common concern. Insufficient water supply may result in reduced tree growth, yield and fruit quality due to water stress. Excessive irrigation, on the other hand, may increase nutrient leaching, water-logging problems, incidence of pests and diseases, and the associated cost of frequent operation and maintenance of the irrigation system. In addition, unmanaged irrigation may lead to adverse environmental effects such as agrochemical leaching into groundwater aquifers, reduced water reservoir, and water and soil salinity. Optimizing water applications by scheduling irrigation to fruit orchards may increase water conservation, reduce production costs, and increase tree growth and yield. Irrigation scheduling is especially important in horticultural crops because net returns are normally higher than those of other crops [1].

According to Hillel [2], the main issue with irrigation management is to determine the frequency, quantity, and timing of irrigation to optimize crop growth and productivity. However, irrigation scheduling and management of fruit crops where rain falls in sufficient quantities in temperate, tropical and subtropical regions is not well established. For example, irrigation was not a common practice in fruit orchards in the humid-temperate regions such as New York, USA. However, in recent decades, irrigation has become more common since it was proven to increase growth and promote early production of high-density apple orchards [3]. Availability of weather data allows the use of evapotranspiration (ET) predictions as a basis for irrigation scheduling [4]. Similar irrigation scheduling approaches were reported by Ebel [5, 6]. Irrigation based on climatic data, is the method commonly used to schedule irrigation of apple orchards in North-Eastern United States.

South Florida is the main region in the continental United States where subtropical and tropical fruit crops are grown. In this region, trees are commonly irrigated at rates and frequencies based mainly on grower's experience and observations of crop growth and yield rather than on quantitative scientific information [7-9]. According to a survey by Muñoz-Carpena [10], 64.3\% of fruit growers irrigate trees based on rainfall frequency and quantity. Problems concerning variability in irriga- 
tion duration and frequency were rated high among tropical fruit growers [11], which highlight the need for a better understanding of irrigation requirements of these crops.

Measurement of soil water content and soil matric potential provide an index of the rate at which water is taken up by the plant or lost from the root zone. Soil water content and potential is therefore most useful in conjunction with information about the soil-plant-atmosphere system [12]. Water extraction from the soil is dependent on plant properties that determine the plant water potential $(\Psi)$ at which a particular plant species can continue to grow and extract water from the soil [13].

Although climate- and soil-based methods provide a means for estimating irrigation amount and timing, they do not take into account the variability between fruit tree species and cultivars, growth stage, or the response of trees to soil moisture deficit. The water refill point, which is the lowest possible soil water content with no decrease in yield or fruit quality, varies among different tree varieties, rootstocks, soils and seasons [14,15]. Several physiological variables are used as indicators of tree water status. Among the most frequently used is tree water potential $[16,17]$.

It is often beneficial to use both soil and plant factors for irrigation scheduling. An integrated approach utilizing soil and plant factors suggested by Buss [18] included soil surveying to determine soil properties and available soil moisture content and crop factors that included crop type, canopy size, rooting width and depth, and crop density. Irrigation scheduling was then planned from a combination of available water data, crop water extraction rates, and the irrigation system layout. Physiological processes in fruit trees such as water potential and gas exchange are sensitive to changes in soil water content $[17,19]$. These physiological variables, growth, and fruit production should be correlated with soil water content prior to determining the appropriate amount of water to apply to an orchard. Little is known about the response of temperate fruit crop, such as apple, and tropical fruit crop, such as star-fruit, to changes in soil water content under field conditions in humid-temperate and subtropical climates. This paper discusses the relationship between soil water content and water potential of apple and star-fruit trees grown in irrigated orchards using climate-based (ET) and soil-based (capacitance probes) irrigation scheduling methods.

\section{MATERIALS AND METHODS}

\subsection{Apple Response to Soil Water Content}

Experimental site and treatments. Young apple trees (Malus domestica Borkh.) (cv. "Gala" on M.9 rootstock) were planted on May 28, 1996 at a spacing of $2 \mathrm{~m}$ within row and $4 \mathrm{~m}$ between rows at the New York State Agricultural Experiment Station at Geneva, NY. The soil at the experimental site is fine Lima silt loam, Glossoboric Hapludalf, which is moderately well-drained [20]. The soil is fine-textured with high water holding capacity and has a hard pan at about $50 \mathrm{~cm}$ below the soil surface. A total of 20 treatments consisting of 18 irrigation treatments and two non-irrigated controls were applied during the growing season from Jun. to Sept. of 1997. The irrigation treatments were a factorial combination of two irrigation frequencies (daily and weekly); three irrigation methods (one-line trickle per row, two-trickle lines per row, and microsprinklers); and three irrigation amounts (50\% ET, $75 \% \mathrm{ET}$, and $100 \% \mathrm{ET})$. The two non-irrigated control treatments were rain-excluded and rainfed. The rainfed treatment received only natural rainfall, while plastic rain-shelters were used to exclude rainfall in rain-excluded treatments [21]. A total of six replications were used, within each replication, there were two trees per plot. Each plot was separated from the next by one McIntosh/M.9 apple tree. Blocking was done by location in the field and initial trunk diameter where the total number of test trees was 240. The experiment was bounded by guard rows of Gingergold/M.9 apple trees. After planting, the trees were pruned to five lateral branches located between $53 \mathrm{~cm}$ and $95 \mathrm{~cm}$ from the rootstock/scion union. All trees were given $20 \mathrm{~L}$ of a dilute starter fertilizer solution (31.4 g N, $13.6 \mathrm{~g} \mathrm{P}_{2} \mathrm{O}_{5}$, and $13.6 \mathrm{~g} \mathrm{~K}_{2} \mathrm{O}$ ) and then fertilized with 113 grams of $\mathrm{CaNO}_{3}$ per tree two weeks after planting.

Irrigation scheduling. Irrigation was scheduled by calculating ET using pan evaporation measurements adjusted by a crop coefficient. Evaporation data were collected from a US Weather Bureau Class A evaporation pan (Epan) located at about $1.75 \mathrm{~km}$ from the site. Epan was adjusted by a crop coefficient (Kcrop) to calculate ET. The crop coefficients used were those developed for mature apple trees [22]. Their values were adjusted for the small canopy size by the method proposed by Ley [22]. Daily water deficits were calculated and then irrigation time in hours was calculated on a daily basis. For the daily treatments, irrigation time was adjusted every day, likewise for the weekly treatments, daily irrigation time was summed and applied once a week.

Soil moisture content measurements. A neutron probe (CPN Model 503 DR Hydroprobe, CPN Corporation, Marines, CA) was used to determine soil moisture content (SMC). Neutron probes provide non-destructive and repetitive soil moisture measurements regardless of the soil condition at several locations in the field [23]. Weekly soil moisture measurements were taken at every $15 \mathrm{~cm}$ depth through the soil profile to $75 \mathrm{~cm}$ below the soil surface. Neutron probe aluminum access tubes were installed at $30 \mathrm{~cm}$ from the trunk of the trees. 
Stem water potential measurements. Stem water potential $\left(\psi_{\mathrm{s}}\right)$ was measured between 1100 and 1400 HRS using a pressure chamber (Soil Moisture Equipment Corp., Santa Barbara, Calif.). Stem water potential was determined using a fully matured leaf enclosed in a reflective plastic bag for $1 \mathrm{hr}$ to suppress transpiration and allow stem water potential to equilibrate with leaf water potential [24-26]. Three mature leaves were used per tree for stem water potential measurement.

\subsection{Star-Fruit Response to Soil Water Content}

Experimental site and plant material. An orchard of 8 -year-old "Arkin" star-fruit trees grafted onto Golden Star rootstock were used for this study. The trees were planted with $4.5 \mathrm{~m}$ within and $6.0 \mathrm{~m}$ between rows and surrounded by a windbreak. The orchard soil was Krome very gravelly loam soil, loamy-skeletal, carbonatic, hyperthermic, Lithic Udorthents [27]. Fertilizer application, pest management, and fertilization followed standard practice for South Florida's commercial star-fruit production. Trees were irrigated with $89 \mathrm{~L} \cdot \mathrm{h}^{-1}$ microsprinklers with a $360^{\circ}$ wetting area. In the orchard, trees were irrigated at various times and rates to provide a range of SWD over the course of the experiments. The ranges were determined from a preliminary study (Al-Yahyai, unpublished data) and based on the SWD from soil field capacity (FC) to leaf yellowing, which was the first visual sign of water stress. For orchard trees, irrigation was withheld toward the end of the experiment for $121 \mathrm{~d}$ from 1 Aug. to 30 Nov. 2003 to obtain high SWD values.

Soil water measurements. Soil water depletion was determined by continuously measuring soil water content using multisensor capacitance probes (EnviroSCAN, Sentek PTY Ltd., Kent Town, Australia), as recommended for Krome soils in a comparative study with tensiometers and neutron probes [8]. Capacitance probes were installed $60 \mathrm{~cm}$ north of tree trunks in the orchard. The sensors recorded soil moisture content every $30 \mathrm{~min}$ at depths of 10,20,30 and $50 \mathrm{~cm}$. The data were stored in a datalogger and later downloaded to a computer for analysis. Soil water content measurements from sensors placed at the 4 depths were summed and plotted using the EnviroSCAN proprietary system software. Installation of the system in Krome soils was previously described by Al-Yahyai et al. [8] and Núñez-Elisea et al. [10], and technical multisensor capacitance probe specifications were described by Paltineanu and Starr [28].

Irrigation scheduling. Irrigation scheduling was based on soil water depletion from continuously monitoring soil water content with the EnviroScan. EnviroSCAN software was used for plotting soil water depletion (SWD) over time and determining the "full point" (field capacity), the "refill point" (time to irrigate), and the theoretical "onset of water stress", based on the rate of SWD [28]. Irrigation of orchard trees was initiated when SWD reached one of the following levels (where $0 \% \mathrm{SWD}=\mathrm{FC}$ ): $0 \%-8 \% \mathrm{SWD}, 9 \%-11 \% \mathrm{SWD}, 12 \%-$ $14 \%$ SWD, or $15 \%-17 \%$ SWD.

Stem water potential measurements. The procedure for measuring stem water potential $\left(\psi_{\mathrm{s}}\right)$ of star-fruit was similar to that of apple trees mentioned above. Stem water potential was determined periodically on four mature leaves per tree from the orchard that were randomly selected for water potential measurements.

\subsection{Statistical Analysis}

Linear regression analysis was performed with SigmaPlot (SYSTAT Software Inc., Richmond, Cal.) and Inflection point was determined using NONLIN Procedure for SAS (SAS Institute, Inc., Cary, North Carolina, USA).

\section{RESULTS AND DISCUSSION}

\subsection{Apple Response to Soil Water Content}

Soil water content. Neutron probe measurements taken at 15, 30, 45, 60 and $75 \mathrm{~cm}$ indicated that soil moisture content was lowest in the top $15 \mathrm{~cm}$ of the soil profile. Rain-excluded and rainfed treatments showed significantly lower soil moisture content throughout the season in the upper $45 \mathrm{~cm}$ of the soil profile than irrigation treatments. However, there were no significant differences in soil water content among treatments of irrigation frequencies and systems and amounts. Moreover, no significant differences in soil water content were observed among irrigation amounts of $50 \%$ ET, $75 \%$ ET and $100 \%$ ET or between rainfed and rain-excluded treatments throughout the growing season of 1997. During the growing season, calculated water deficit as determined from ET was greater than rainfall for most of the season (Figure 1). In fruit orchards, soil moisture varies according to soil type and characteristics, cultivar and rootstock, and climatic conditions [19,29,30]. Lack of significant differences in soil water content in this study may be attributed to one or all of these factors.

Stem water potential. Stem water potential of rainfed and rain-excluded treatments was significantly lower than that of irrigated trees. However, no significant differences were found among trees irrigated at $50 \% \mathrm{ET}$, $75 \%$ ET, and $100 \%$ ET. No significant correlation between soil water depletion (SWD) and stem water potential was observed (Figure 2). This indicated that soil moisture content was not the only factor that influenced the reduction of stem water potential in non-irrigated 


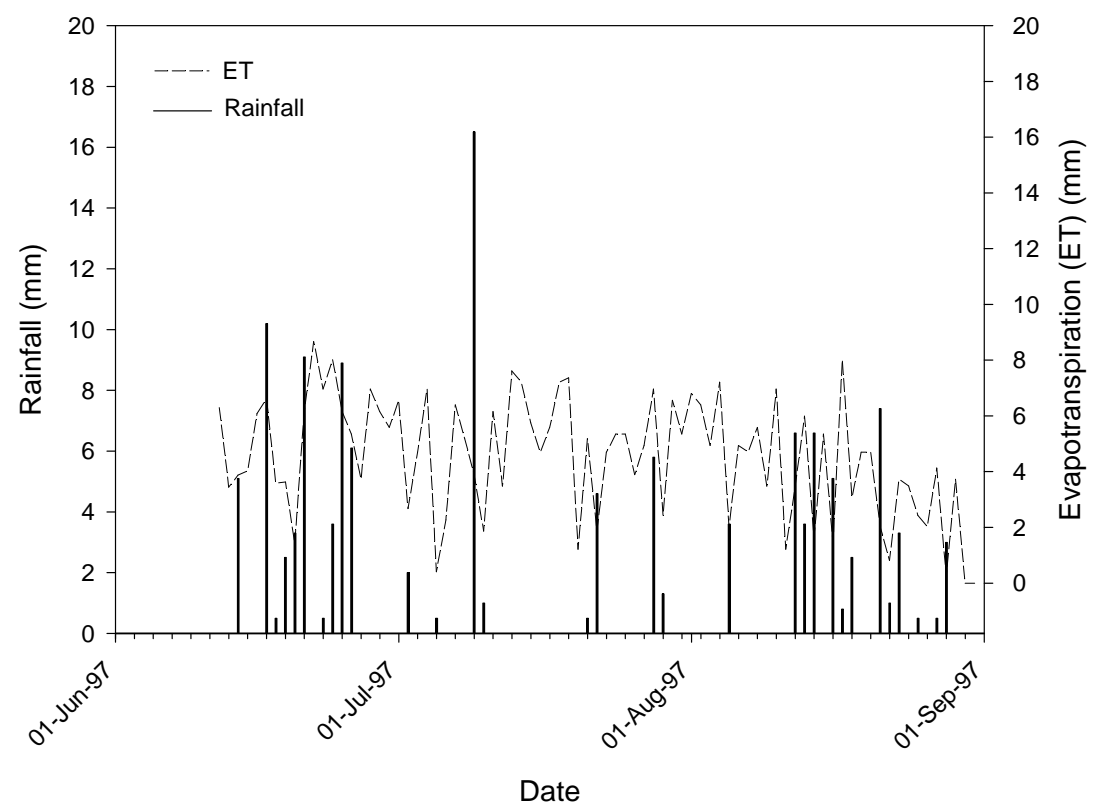

Figure 1. Rainfall and evapotranspiration (ET) during apple growing season of 1997 in Geneva, New York.

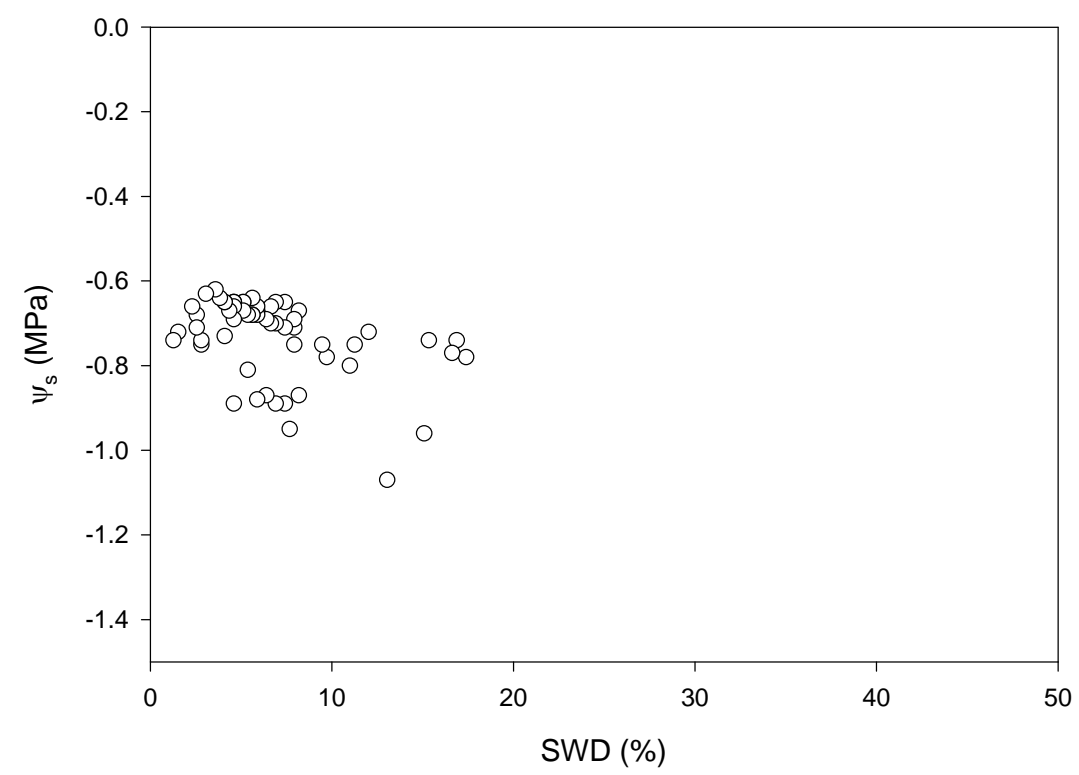

Figure 2. Soil water depletion (SWD) and stem water potential $\left(\Psi_{\mathrm{S}}\right)$ of "Gala" apple on M.9 rootstock grown in Geneva, New York.

treatments when compared to irrigated treatments. According to Goode and Higgs [31], if soil moisture is high and evaporative demand is low, plant water potential will remain high and irrigation will have a negligible effect on plant water status. Although plant stem water potential and soil water content were increased by irrigation, trees have not reached a critical water stress level and did not respond to various amounts of water applied. Ebel et al. [32] reported that stem water potential of fruit trees change little over a range of soil water depletion that can reach $80 \%$. Thus corresponding reduction in growth and yield response can only be detected when trees are severely stressed at soil water depletion (SWD) levels below $25 \%[30]$.

\subsection{Star-Fruit Response to Soil Water Content}

Soil water content. In southern Florida, where tropi- 
cal and subtropical fruit crops are grown, rainfall patterns and evapotranspiration (ET) followed historical records. Of the $1611 \mathrm{~mm}$ of total rainfall in 2003, 79.5\% occurred between May and Oct. (Figure 3). Total ET was estimated as $1129 \mathrm{~mm}$ with $67 \%$ occurred during the same period (Figure 3). Nonetheless, the distribution within the year, however, varied greatly among and within months and daily rainfall ranged from 0 to $93 \mathrm{~mm}$ and ET from $0.99 \mathrm{~mm}$ to $5.33 \mathrm{~mm}$. During the winter months there was $20 \%$ higher ET than rainfall. Irrigation of star-fruit orchard was scheduled using changes in soil moisture content over time as determined by multisensor capacitance probes. Continuous measurement of soil water content in tropical fruit orchards in Krome very gravelly loam soils was determined using multisensor capacitance probes $[7,8,33,34]$. Irrigation was applied to the "full point" (field capacity) to maintain soil water content above the theoretical "onset of water stress", the point at which the ET rate is significantly reduced [7] and [34]. In the present study, soil water content declined in a typical stepwise pattern over the course of the experiment and never reached the "onset of stress" levels in the orchard.

Stem water potential. The soil water depletion (SWD) of star-fruit orchard remained below $30 \%$ throughout the year 2003. Within the range of SWD from $0 \%$ to $30 \%$, stem water potential remained ( $\Psi \mathrm{s}$ ) above $-1.0 \mathrm{MPa}$ and did not significantly correlate with SWD (Figure 4). Therefore, within a $0 \%$ to $30 \%$ SWD range, there was no significant effect of $\Psi$ s on leaf gas exchange, presumably due to sufficient soil water content in the orchard from frequent rainfall and capillary rise to the root zone from the water table which was $1-2 \mathrm{~m}$ below the soil surface [35]. Similarly, in a study of mango trees in Krome soil, predawn water potential ranged from -0.3 to $-0.5 \mathrm{MPa}$ and there were no significant differences in tree physiological processes were observed between irrigated and non-irrigated trees [36]. Ismail et al. [37,38] observed that withholding water for 1,2 , or 4 weeks resulted in midday $\Psi_{\mathrm{L}}$ of -1.3 to $-1.5 \mathrm{MPa},-2.0$ to $-2.5 \mathrm{MPa}$, or $-2.9 \mathrm{MPa}$ of container-grown star-fruit trees, respectively, in comparison to trees irrigated at field capacity that had a $\Psi_{\mathrm{L}}$ of $-0.9 \mathrm{MPa}$.

Al-Yahyai et al. [17] reported that stem water potential of star-fruit trees in containers in the greenhouse was above $-1.0 \mathrm{MPa}$ when SWD increased from $0 \%$ to $60 \%$ above which there was a sharp decrease in stem water potential. A nonlinear reanalysis of the data showed that the reflection point at which stem water potential was reduced linearly with a decline in SWD was 58\% (Figure 5). A similar trend was observed in container-grown trees with a sharp decrease in stem water potential when SWD reached 50\% under field conditions [17]. The ability of star-fruit trees to regulate their water potential was attributed to osmotic adjustment through increased levels of proline [37] (Ismail et al., 1994) and a reduction in stomatal conductance [37-39].

Stem water potential is a useful indicator of water stress and thus can be used for irrigation management [26,40,41]. Al-Yahyai et al. [17] found that physiological processes such as leaf gas exchange of container-grown star-fruit trees in the field and in a greenhouse was more closely correlated with stem water potential than with SWD. In this study, $\Psi$ s was not influenced by SWD of up

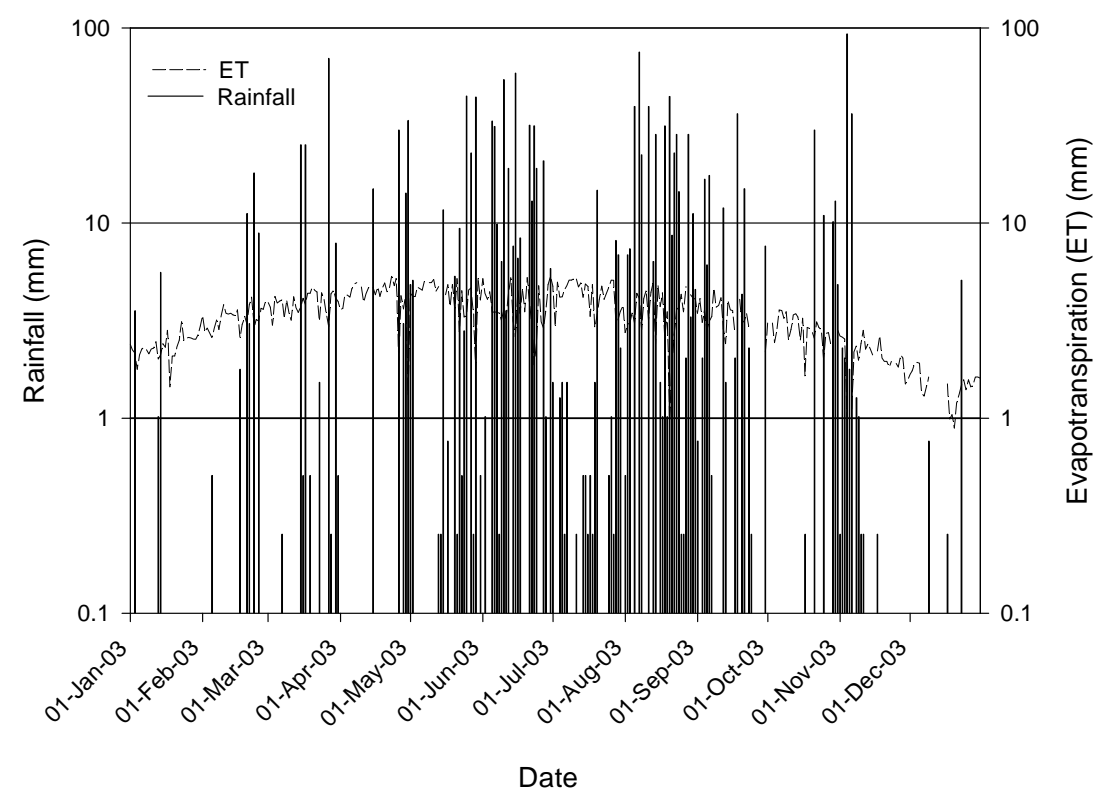

Figure 3. Rainfall and evapotranspiration (ET) during star-fruit growing season in 2003 in Homestead, Florida (Y axes on log scale). 


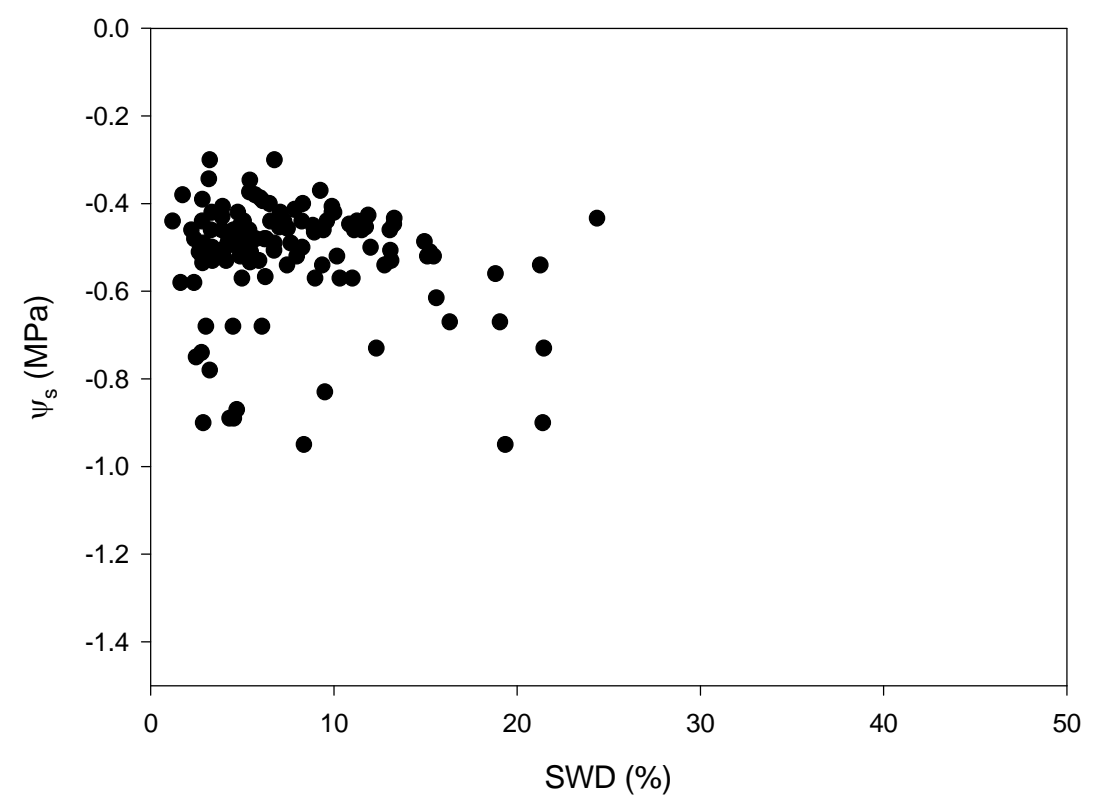

Figure 4. Soil water depletion (SWD) and stem water potential $\left(\Psi_{\mathrm{S}}\right)$ of "Arkin" star-fruit on Goldenstar rootstock grown in Homestead, Florida.

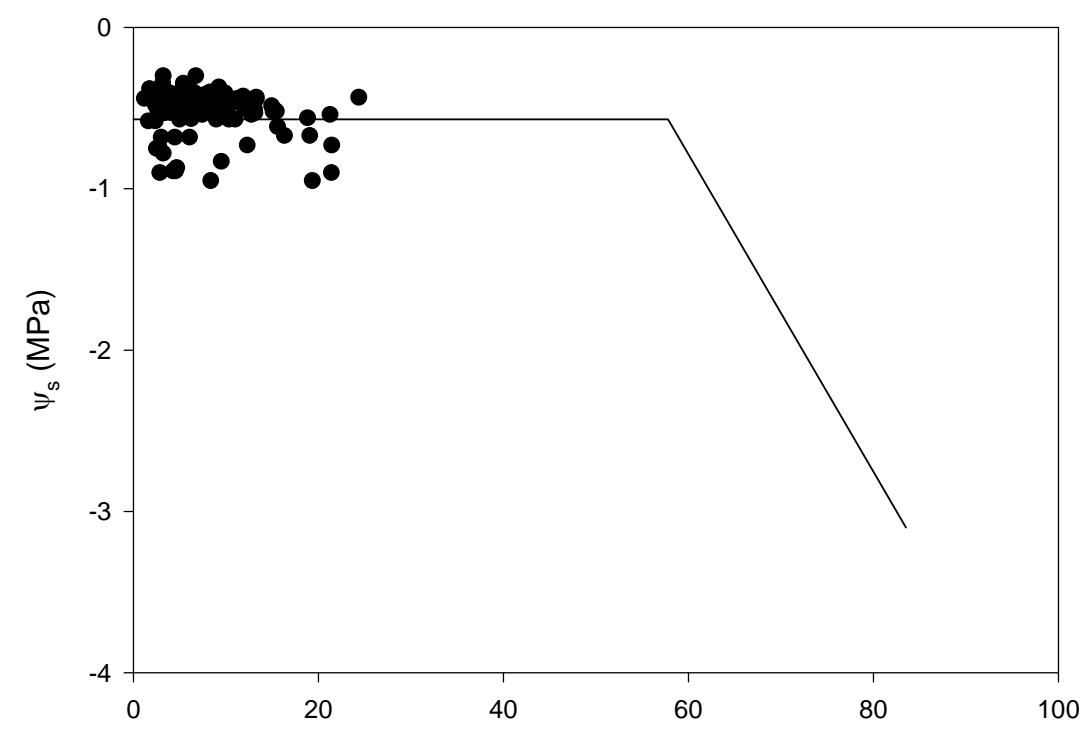

SWD (\%)

Figure 5. Soil water depletion (SWD) and stem water potential $\left(\Psi_{\mathrm{S}}\right)$ of "Arkin" star-fruit on Goldenstar rootstock grown in an orchard in Homestead, Florida. The data are plotted against nonlinear model of greenhouse-grown star-fruit subjected to continuous soil water depletion (model data from Al-Yahyai et al. [17]).

to $30 \%$ under field conditions (Figures $\mathbf{4}$ and $\mathbf{5}$ ). This is despite continuous monitoring of water status which indicated that irrigation was required. Measurements of $\Psi \mathrm{s}$ and net $\mathrm{CO}_{2}$ assimilation (A) chosen randomly at a point beyond the theoretical "onset of water stress" point as measured with multisensor capacitance probes indicated that growers frequently applied more water than needed by trees (Figure 6). This also suggests that using soil water monitoring devices to schedule irrigation without correlation to tree water status may lead to over irrigation. This was confirmed with results from Al-Yahyai et al. [9] who applied from 623 to 890 liters per tree per year during 


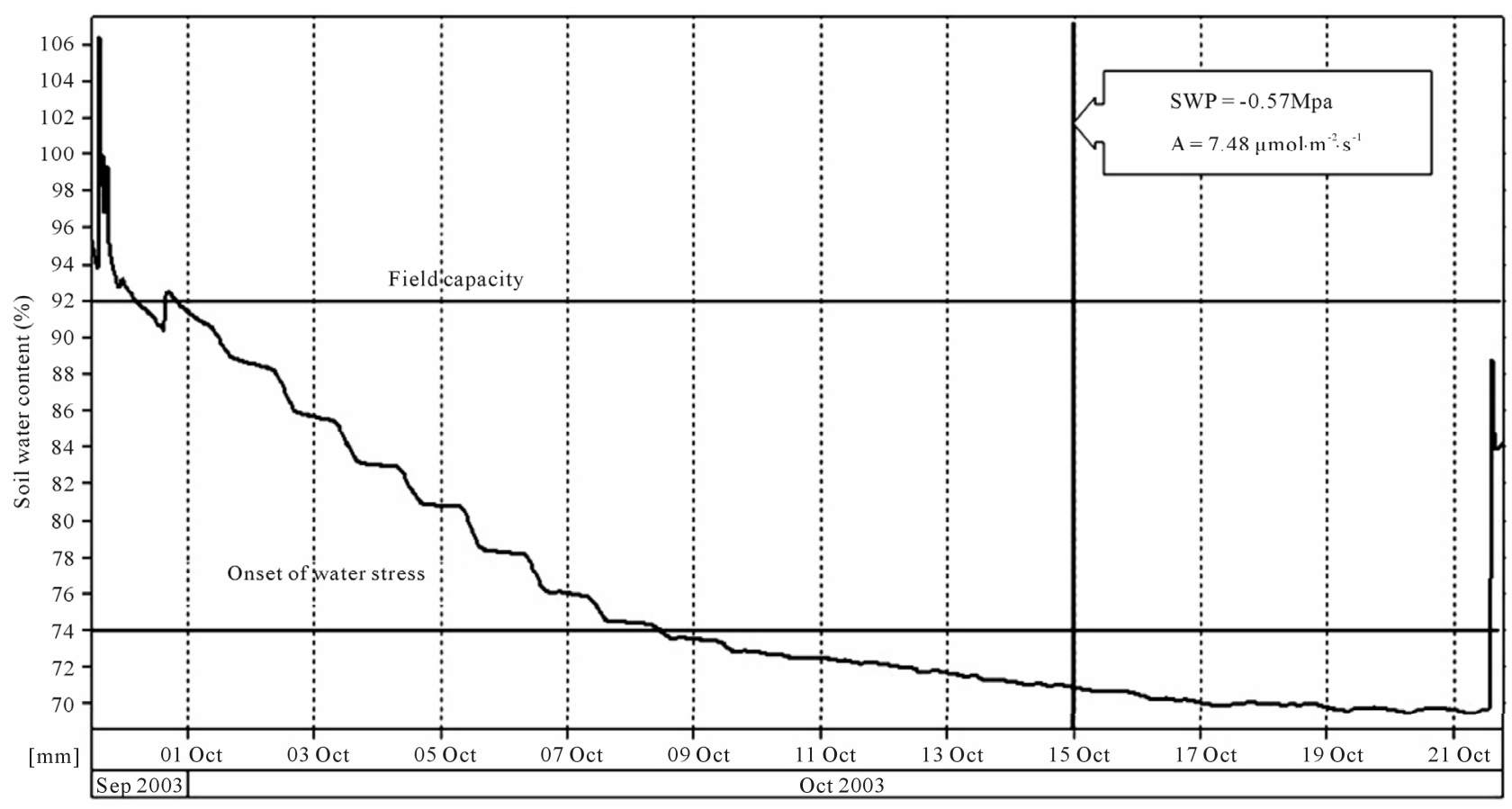

Calendar date

Figure 6. Soil water depletion (SWD) as measured with capacitance probes (EnviroSCAN) in an 8-year-old starfruit orchard in Krome soils. Points of "field capacity" and "onset of water stress" were determined based on the pattern of soil water depletion. Measurements of stem water potential (SWP) and net $\mathrm{CO}_{2}$ assimilation (A) indicated by the vertical double-line on the $\mathrm{x}$-axis were chosen randomly at a point beyond the theoretical "onset of water stress" point.

22 hours of irrigation. This is considerably less than $0.1 \%$ of the amount of water applied by the star-fruit growers who irrigate from 548 to $2190 \mathrm{hrs}$ of irrigation yearly as much as to 21,700 to 115,739 liters per tree per year.

Stem water potential relationship to leaf water potential. It has been suggested that leaf water potential $\left(\Psi_{\mathrm{L}}\right)$ is a less reliable measure when making irrigation scheduling decisions for fruit trees than stem water potential $\left(\Psi_{\mathrm{S}}\right)$ due to its inherent variability under field conditions $[25,40,42]$. Enclosing leaves in a reflective, dark plastic bag for $1-2 \mathrm{~h}$ prior to water potential measurements will reduce transpiration until an equilibrium is achieved between the $\Psi_{\mathrm{L}}$ and the stem water potential [24], thus providing a more precise method of determining tree water status $[25,26,40,42]$. In this study, $\Psi_{\mathrm{L}}$ and $\Psi_{\mathrm{S}}$ from the same branch were measured within 2 min of each other to determine their relationship. There was a strong relationship $\left(\mathrm{r}^{2}=0.85\right)$ between $\Psi_{\mathrm{L}}$ and $\Psi_{\mathrm{S}}$ in orchard trees (Figure 7), despite the narrow water potential range of -0.3 to $-1.1 \mathrm{MPa}$. Jones [13] suggested that either stem water potential or $\Psi_{\mathrm{L}}$ may be used to assess the effect of water stress on a particular tree response that is assumed being affected by tree water status. Our results with star-fruit trees appeared to confirm this.

\section{CONCLUSIONS}

Results from this study showed that irrigation scheduling of apple and star-fruit based on climatic parameters (ET) and measurements of soil water content, respectively, did not affect stem water potential under field conditions. Soil water content and stem water potential $(\Psi \mathrm{s})$ of apple trees irrigated at 50\% ET, 75\% ET, and $100 \%$ ET did not significantly differ and no correlation between soil and tree water status was found. Similarly, in a subtropical climate of south Florida, stem water potential of star-fruit trees was not influenced by irrigation based on continuous measurement of soil water depletion below $30 \%$. In addition to tree factors, lack of correlation between soil water depletion and stem water potential in apple may have been due to frequent rainfall and high water holding capacity of the soil. In, Star-fruit high rainfall and capillary rise to the root zone from the water table, located at 1 to $2 \mathrm{~m}$ below the soil surface, was sufficient to maintain adequate soil water even after several weeks of no irrigation.

Measurements of soil water content, plant water status or climatic data are all practical and feasible methods of irrigation scheduling of fruit crops. Irrigation scheduling based on soil water content has been widely adopted due to the availability and ease of use of various devices that monitor soil water status either discretely (e.g. ten- 
siometers, neutron probes) or continuously (e.g. multisensor capacitance probes). In recent decades, management of irrigation based on tree water status has gained interest. Several studies have determined that tree stem water potential, gas exchange measurements, sap flow, and stem daily shrinkage, among other tree measurements, can be utilized for making decisions about irrigation of fruit crops. For several fruit crops, yield is more highly correlated with stem water potential than with soil water potential, thus validating the use of irrigation decisions based on plant water status as well as soil water content.

Despite the lack of differences among treatments, substantial savings of water can be gained from irrigation scheduling using climatic and soil water measurement devices of fruit crops. However, irrigation based on such methods should be correlated to tree water status as indicated by physiological processes such as stem water potential. This is especially important in regions where water is scarce such as the Arabian Peninsula.

\section{ACKNOWLEDGEMENTS}

The author acknowledges the support of Terence Robinson and Alan Lakso, Cornell University, in conducting the apple study. The author is also grateful to Bruce Schaffer and Frederick S. Davies, University of Florida, for their support during the study of star-fruit. Results of this work was presented during the International Conference on Economic Incentives \& Water Demand Management, 18-22 March 2006, Sultan Qaboos University, Oman. Sultan Qaboos University is acknowledged for partially funding this research work.

\section{REFERENCES}

[1] Fereres, E. (1997) Irrigation scheduling of horticultural crops. Acta Horticulturae, 449, 253-258.

[2] Hillel, D. (1998) Environmental soil physics. Academic Press, New York.

[3] Robinson, T. and Stiles, W. (1995) Maximizing the performance of young apple trees. New York Fruit Quarterly, 3, $10-16$.

[4] Hutmacher, R.B., Nightingale, H.I., Rolston, D.E., Biggar, J.W., Dale, F., Vail, S.S. and Peters, D. (1994) Growth and yield responses of almond (Prunus amygdalus) to trickle irrigation. Irrigation Science, 14, 117-126. doi:10.1007/BF00193133

[5] Ebel, R.C., Proebsting, E.L. and Patterson, M.E. (1993) Regulated deficit irrigation may alter apple maturity, quality, and storage life. HortScience, 28, 141-143.

[6] Ebel, R.C., Proebsting, E.L. and Evans, R.G. (1995) Deficit irrigation to control growth in apple and monitoring fruit growth to schedule irrigation. HortScience, 30, 1229-1232.

[7] Schaffer, B. (1998) Flooding response and water-use efficiency of subtropical and tropical trees in an environ- mentally-sensitive wetland. Annals of Botany, 81, 475481. doi:10.1006/anbo.1998.0593

[8] Al-Yahyai, R., Schaffer, B. and Davies, F.S. (2003) Monitoring soil water content for irrigation scheduling in a carambola orchard in a gravelly limestone soil. Proceedings of the Florida State Horticultural Society, 116, 37-41.

[9] Al-Yahyai, R., Davies, F.S., Schaffer, B. and Crane, J.H. (2005) Effect of soil water depletion on growth, yield, and fruit quality of carambola in gravelly loam soil. Proceedings of the Florida State Horticultural Society, 118, 237-241.

[10] Muñoz-Carpena, R., Crane, J., Israel, G. and Yurgalevitch, C. (2003) Water conservation survey of Miami-Dade County agricultural and golf course commercial water users. Proceedings of the Florida State Horticultural Society, 116, 15-21.

[11] Li, Y., Crane, J., Boman, B. and Balerdi, C. (2000) Irrigation management survey for tropical fruit crops in South Florida. Proceedings of the Florida State Horticultural Society, 113, 40-42.

[12] Campbell, G.S. and Campbell, M.D. (1982) Irrigation scheduling using soil moisture measurements: Theory and practice. Advances in Irrigation, 1, 25-42.

[13] Jones, H.G. (1990) Physiological aspects of the control of water status in horticultural crops. HortScience, 25, 19-26.

[14] Braun, P., Aspinall, D. and Lenz, F. (1989) The use of physiological indicators of water status in irrigation scheduling in citrus. Acta Horticulturae, 240, 267-270.

[15] Jones, H.G. (2004) Irrigation scheduling: Advantages and pitfalls of plant-based methods. Journal of Experimental Botany, 55, 2427-2436. doi:10.1093/jxb/erh213

[16] Hsiao, T. (1990) Measurements of plant water status. In: Steward, B. and Nielsen, D., Eds., Irrigation of Agricultural Crops, Agronomy Monographs No. 30, ASA, Madison, Wis, 243-279.

[17] Al-Yahyai, R., Schaffer, B. and Davies, F.S. (2005) Physiological response of carambola to soil water depletion. HortScience, 40, 2145-2150.

[18] Buss, P. (1989) Irrigation scheduling for horticulture: An integrated approach. Acta Horticulturae, 240, 261-270.

[19] Naor, A. and Cohen, S. (2003) Sensitivity and variability of maximum trunk shrinkage, midday stem water potential, and transpiration rate in response to withholding irrigation from field-grown apple trees. HortScience, $\mathbf{3 8}$, 547-551.

[20] USDA (United States Department of Agriculture) (1958) Soil survey. Ontario and Yates Counties, New York, Series 1949, No. 5, 56-57.

[21] Jones, H.G., Luton, M.T., Higgs, K.H. and Hamer, P.J. (1983) Experimental control of water status in an apple orchard. Journal of Horticultural Science, 58, 301-316.

[22] Ley, T.W. (1994). Using PAWS and AgriMet for irrigation scheduling. In: Williams, K.M. and Ley, T.E. Eds., Tree Fruit Irrigation, Good Fruit Grower, Washington DC, 7177. 
[23] Chanasyk, D.S. and Naeth, M.A. (1996) Field measurement of soil moisture using neutron probes. Canadian Journal of Soil Science, 76, 317-323. doi:10.4141/cjss96-038

[24] Begg, J.E. and Turner, N.C. (1970) Water potential gradients in field tobacco. Plant Physiology, 46, 343-346. doi:10.1104/pp.46.2.343

[25] McCutchan, H. and Shackel, K. (1992) Stem-water potential as a sensitive indicator of water stress in prune trees (Prunus domestica L. cv. French). Journal of the American Society for Horticultural Science, 117, 607611.

[26] Shackel, K.A., Ahmadi, H., Biasi, W., Buchner, R., Goldhamer, D., Gurusinghe, S., Hasey, J., Kester, D., Krueger, B., Lampinen, B., McGourty, G., Micke, W., Mitcham, E., Olson, B., Pelletrau, K., Philips, H. Ramos, D., Schwankl, L., Sibbett, S., Snyder, R., Southwick, S., Stevenson, M., Thorpe, M., Weinbaum, S. and Yeager, J. (1997) Plant water status as an index of irrigation need in deciduous fruit trees. HortTechnology, 7, 23-29.

[27] Noble, C.V., Drew, R.W. and Slabaugh, V. (1996) Soil survey of Dade County area, Florida. U.S. Department of Agriculture, Natural Resources Conservation Service, Washington DC.

[28] Paltineanu, I.C. and Starr, J.L. (1997) Real-time soil water dynamics using multisensor capacitance probes: Laboratory calibration. Soil Science Society of America Journal, 61, 1576-1585. doi:10.2136/sssaj1997.03615995006100060006x

[29] Lord, W.J., Michelson, L.F. and Filed, D.L. (1963) Response of irrigation and moisture use by McIntosh apple tree in Massachusetts. Experiment Station Bulletin, 537, $1-23$.

[30] Forshey, G.G. and Dominick, B.A. (1965) Irrigation of apples in the Hudson Valley. New York State Agricultural Experiment Station Bulletin, 809.

[31] Goode, A.J. and Higgs, K.H. (1973) Water, osmotic and pressure potential relationships in apple leaves. Journal of Horticultural Science, 48, 203-215.

[32] Ebel, R.C., Proebsting, E.L. Evans, R.G. and Ley, T.W. (1988) "Delicious" tree and fruit response to duration of drought. HortScience, 23, 723.
[33] Núñez-Elisea, R., Schaffer, B., Zekri, M., O’Hair, S.K. and Crane, J.H. (2001) In situ soil-water characteristic curves for tropical fruit orchards in trenched calcareous soil. HortTechnology, 11, 65-69.

[34] Zekri, M., Núñez-Elisea, R., Schaffer, B., O’Hair, S.K. and Crane, J.H. (1999) Multisensor capacitance probes for monitoring soil water dynamics in the oolitic limestone soil of South Florida. Proceedings of the Florida State Horticultural Society, 112, 178-181.

[35] Al Al-Yahyai, R., Schaffer, B., Davies, F.S. and Crane, J.H. (2005) Four levels of soil water depletion minimally affect carambola phenological cycles. HortTechnology, 15, 623-630.

[36] Larson, K., Schaffer, B. and Davies, F.S. (1989) Effect of irrigation on leaf water potential growth and yield of mango trees. Proceedings of the Florida State Horticultural Society, 102, 226-228.

[37] Ismail, M.R., Burrage, S.W., Tarmizi, H. and Aziz, M.A. (1994) Growth, plant water relations, photosynthesis rate, and accumulation of proline in young carambola plants in relation to water stress. Scientia Horticulturae, 60, 101114. doi:10.1016/0304-4238(94)90065-5

[38] Ismail, M.R., Yusaf, M.K. and Masturi. A. (1996) Growth and flowering of water stressed star-fruit plants and response to ameliorated water stress. Proceedings of the International Conference on Tropical Fruits, Kuala Lampur, Malaysia, 2, 97-106.

[39] Razi, M.I., Awang, M. and Razlan, S. (1992) Effect of water stress on growth and physiological processes of Averrhoa carambola. Acta Horticulturae, 321, 505-509.

[40] Naor, A. (2000) Midday stem water potential as a plant water stress indicator for irrigation scheduling in fruit trees. Acta Horticulturae, 537, 447-454.

[41] Stern, R.A., Meron, M., Naor, A. Wallach, R., Bravdo, B. and Gazit, S. (1998) Effect of fall irrigation level in "Mauritius" and "Floridian" lychee on soil and plant water status, flowering maturity, and yield. Journal of the American Society for Horticultural Science, 123, 150155.

[42] Garnier, E. and Berger, A. (1985) Testing water potential in peach trees as an indicator of water stress. Journal of Horticultural Science, 60, 47-56. 